\title{
Research Paper: Does the Nine-test Screening Battery Predict Lumbar Hyperlordosis in Adolescent Boys?
}

\author{
Mohammad Shahabi $^{1^{*}}$ (D), Hooman Minoonejad ${ }^{1}$ (D), Mohammad Karimizadeh Ardakani ${ }^{1}$ (D)
}

1. Department of Health and Sport Medicine, Faculty of Physical Education and Sport Sciences, University of Tehran, Tehran, Iran.

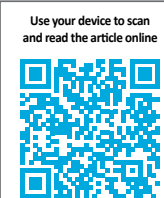

Citation Shahabi M, Minoonejad H, Karimizadeh Ardakani M. Does the Nine-test Screening Battery Predict Lumbar Hyperlordosis in Adolescent Boys? Physical Treatments. 2021; 11(1):63-74. http://dx.doi.org/10.32598/ptj.11.1.464.1

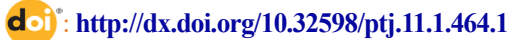

(c) (i) (5)

Article info:

Received: 13 Jun 2020

Accepted: 20 Sep 2020

Available Online: 01 Jan 2021

Keywords:

Lordosis, Prediction,

Nine-test screening battery,

Functional movement screen,

Adolescence

\section{A B S T R A C T}

Purpose: Lumbar hyperlordosis is one of the main physical abnormalities that occur in the lumbopelvic region and affect the body movement system in daily life. This condition can also lead to chronic injuries and pain. The present study aimed to investigate the ability of the ninetest screening battery to predict the incidence of lumbar hyperlordosis in adolescent boys.

Methods: This causal study described and analyzed the data with a cross-sectional design. In this regard, 60 adolescents (age range: 13 to 15 years) were selected. After the initial assessments, they were assigned into two groups: the lumbar hyperlordosis group $(n=31)$ and the normal lordosis group $(n=29)$. The angle of lumbar lordosis curvature and functional movements were measured using a flexible ruler and the nine-test screening battery instruction, respectively. The obtained data were analyzed using the logistic regression test at a significance level of 0.05, in SPSS V. 24.

Results: The examination of the coefficients of predictive variables showed that the Wald test is statistically significant for deep squat $(\mathrm{P}=0.023)$ and straight leg raise $(\mathrm{P}=0.033)$. Also, these variables significantly contribute to the predictability of the model and the likelihood of lumbar hyperlordosis.

Conclusion: Based on the results, the nine-test screening battery can predict the occurrence of lumbar hyperlordosis in adolescent boys through the components of deep squat and straight leg raise.

* Corresponding Author:

Mohammad Shahabi, MA.

Address: Department of Health and Sport Medicine, Faculty of Physical Education and Sport Sciences, University of Tehran, Tehran, Iran.

Phone: +98 (935) 2659213

E-mail: mo.shahabi94@gmail.com 


\section{Highlights}

-9TSB was used to predict the likelihood of lordosis.

-The tests included deep squat, one-legged squat, in-line lunge, active hip flexion, straight leg raises, push up, diagonal lift, seated rotation and functional shoulder mobility.

-The Wald test is statistically significant for the deep squat 0.023 and for straight leg raise 0.033 .

-These variables contribute significantly to the predictability of the model and the likelihood of lumbar hyper lordosis.

\section{Plain Language Summary}

Spinal abnormalities may have negative effects on a person's quality of life. Among these abnormalities, lumbar hyper lordosis is one of the most important and common. It is better to do screening and physical evaluation programs at an early age so that if there are postural problems, the necessary prevention can be done. There are several ways to measure and evaluate the human body, the evaluation of movement patterns is one of the most important and efficient. Movement patterns mean how people typically perform their daily movements and activities, and whether or not these patterns meet the standard defined for body anatomy. The aim of this study was to use a guideline for measuring movement patterns to predict the likelihood of lumbar deformity. The instructions we used in this study included 9 tests that challenged most parts of the body. Among them, the movements that challenged the lumbar and pelvic areas the most were able to create a clean slate between normal people and people with lumbar hyper lordosis. In other words, people with lumbar hyper lordosis are weak in performing movements that play a greater role in the spine and pelvis, and show lower quality movements than normal people.

\section{Introduction}

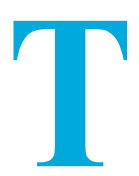

oday, measuring the quality of movement patterns is becoming more and more important. All the sections and groups of society need to perform functional movements without limitation and pain during daily activities. The human movement system is coherent; defects in this system lead to compensatory states and adaptations to other systems, so that it results in dysfunction, changes in arthrokinematic joints, interaction force pairs, muscle length-tension relationship, and neuromuscular efficiency [1]. However, the harmonious relationships of joints, muscles, and nerves are necessary to maintain a natural posture. Therefore, a malfunction will result in a postural disorder. Disruption in the posture can also cause performance defects by changing sensory inputs. The repetition of the wrong pattern exacerbates this vicious cycle until the individual adapts to the pattern and the wrong posture remains [1]. Besides, spinal deformities are another factor affecting the pattern of movement $[2,3]$.

Natural curves in the spine reduce body pressure and deformities [4]. Among the arches of the spine, lumbar lordosis is the lowest curvature of the spine [5]. Lum- bar lordosis is an internal (abdominal) curvature of the lumbar spine caused by the wedge-shaped property of the lumbar vertebrae and intervertebral discs $[5,6]$. This area is exposed to many dangers and anomalies due to the weight-bearing related to the upper body [7]. This can lead to many problems, including stress focus on specific vertebral structures, lower back pain, and the disorders of postural stability and patient function [8]. During the period before and after puberty, the body posture undergoes significant changes to achieve a new balance. Eventually, these changes in the developmental stage lead to deviations in the child and adolescent posture [9]. New data indicate the increasing growth of the various types of spinal deformities, including lordosis, in children and adolescents. Almost one in three children experiences weakness in soft tissues [10], also, $42 \%$ of adolescents in Iran have the lumbar hyperlordosis problem [11].

Functional movement screen is a comprehensive and advanced test that is used to identify specific movement disorders associated with musculoskeletal injuries [12, 13]. These cases should be considered in evaluating functional movements to show the complexity and interaction of cognitive and perceptual components; motor system function; and other factors, such as smooth and flawless motor patterns, limb asymmetry, the range 
of motion limitations, proprioceptive deficiencies, body condition, and pain control [13]. This is done with the accurate tools and the right technology to assess the weaknesses, clear functional limitations, and asymmetries in people's bodies [14].

In this regard, Cook et al. developed seven tests to identify, analyze, and treat functional defects and improve performance and prevent injury [15]. This test consists of seven diverse and widely used fundamental movements in daily life [16] and designed to identify abnormal movement patterns, asymmetry in the limbs, pain, range of motion, defects in profundity, strength, power, postural control, and core stability and it can be implemented in a fast, noninvasive, cheap and easy way [17]. Moreover, the US Tennis Association developed a screen test called the high-performance profile, which is an advanced screening system for assessing movement patterns. The high-performance profile aimed to highlight the weaknesses and deficiencies related to strength and flexibility, as well as identify the areas of the body that athletes need to focus more on [18]. Monitoring and reviewing the tests, Frohm et al. tried to add new tests and eliminate duplicate and unnecessary ones. The purpose of this work was to modify and introduce a more optimal test to evaluate the performance of individuals, especially by applying more challenges to the lumbopelvic region [18]. In the nine-test Screening Battery (9TSB), a total of seven tests were extracted from two different sources, then, two more tests were added to challenge and test the dynamic function of the trunk's flexor muscles and spinal rotators [18].

Studies by the Functional Movement Screen (FMS) test have shown a much higher risk of injury among people with scores below 14 out of 21 FMS [19]. In this regard, Zandi et al. predicted injury in athletes in the public sports by functional movement screen. To this end, 204 athletes in different fields of public sports were evaluated for functional movement, then, their sports injuries during sports competitions were recorded. The results showed that people with an FMS test score of less than 14 were 3.63 times more likely to be injured, compared with other athletes [20]. Also, Haddadnezhad et al. examined the relationship between the scores of FMS test with a history of injury and determined the predictive score of the screenings for injury. The results showed that people without injuries had better scores than injured people. Also, the FMS test scores differed between ankle injury and knee injury groups, compared with the group without injuries. The use of a probability ratio showed that athletes with a score of less than 17 were about 4.7 times more likely to have lower limb injury than those with a higher score [21]. Allafan et al examined the ability of screen tests for functional movements in predicting nonstructural scoliosis in female students [22]. Their results showed a significant inverse relationship between scoliosis with deep squat, forward step, active hip flexion, push-up, and diagonal lift. Moreover, the results of logistic regression analysis showed that a low score on forward step and active hip flexion can predict the possibility of scoliosis incidence [22].

However, studies using the FMS have shown a significantly higher injury risk among individuals with low FMS scores, considering a cut-off score of 14 out of 21 possible points [19]. Still, the sensitivity seems to be low: the receiver operating characteristic curve indicated that the overall predictive validity of the FMS was only slightly better than chance [23]. Some research has been done to evaluate the capability of 9TSB in predicting injuries, but the ability of this test to predict spinal abnormalities is still unknown.

In this regard, Bakken et al. in a prospective study of the $9+$ test, which is an improved test of 9TSB, examined the ability of this test to predict the occurrence of lower limb injuries in elite football athletes. Their results showed no significant relationship between the overall score and the injuries of the lower limbs of athletes $(\mathrm{P}<0.13)$. As stated, the receiver operating characteristic curve analysis showed the area of 0.48 below the curve, besides, no cutoff point could distinguish the injured players from noninjured ones [24]. In a prospective study, Leandersson et al. examined the ability of 9TSB as well as the modified nine-test Screening Battery (M9TSB) to predict the one-year occurrence of lower extremity injuries in elite orienteering athletes. Their results showed no significant relationship between 9TSB $(\mathrm{P}<0.75)$, M9TSB $(\mathrm{P}<0.83)$, and injury. Also, neither 9TSB with $74 \%$ sensitivity and $41 \%$ specificity nor M9TSB with $47 \%$ sensitivity and $61 \%$ specificity did not meet the required capability to predict lower limb injuries [25].

Previous studies have reported different results on the ability of 9TSB to predict the injuries of different sports. However, very few studies have been tested the ability of this test to predict nonstructural deformities, especially in adolescents who are physically in a sensitive period. Given the importance of the prevalence of lumbar hyperlordosis in adolescents and the importance of 9TSB, the question arises as to what is the function of adolescents with hyperlordosis in this test and whether this test can be an appropriate predictive factor. Therefore, the present study aimed to investigate the capability of this test in predicting the possibility of lumbar hyperlordosis. For the first time, this study 
used 9TSB to evaluate functional movements in adolescent boys with lumbar hyperlordosis. Moreover, the deformity condition was monitored in the form of movement patterns, by examining the Frohm test scores in this particular group.

\section{Materials and Methods}

\section{Research design}

This causal study described and analyzed data with a cross-sectional design. The statistical population of the present study consisted of 13- to 15-year-old boys in two groups with lumbar hyperlordosis and with natural lordosis. Thus, 60 adolescents with moderate activity levels were selected using purposive convenience sampling method. The subjects participated in a physical fitness class and the criterion for their average activity was 4 to 6 hours of exercise during the week. The sample size was estimated to be 29 people, using the $G \times$ Power software and with an effect size of $0.75, \alpha=0.05$, and a statistical power of $80 \%$ for each group. After accepting the explanations about the process of the work and being fully aware of the provisions of the tests, all the subjects received and completed the research questionnaire and consent form. Those with a history of surgery or orthopedic problems, as well as deformities other than hyperlordosis, were excluded from the study. Also, inclusion criteria included having a Body Mass Index (BMI) between 18 and $25 \mathrm{~kg} / \mathrm{m}^{2}$, having lumbar lordosis of more than $45^{\circ}$ for the lumbar hyperlordosis group, and lumbar lordosis of less than $40^{\circ}$ for the normal group. Furthermore, the other factors that caused the subjects to leave the research were the feeling of pain and discomfort during the test, the reluctance of the subjects to continue cooperation for any reason, or the researcher's judgment that they were not cooperating.

The study is approved by the Ethics Committee of the University of Tehran, with the code of IR.UT.SPORT. REC.1398.026. Besides, all measurements were performed by the researcher, in health centers and fitness clubs, in Tehran. In each session, the weight and height of the subjects were measured using a personal scale (made in Iran with an accuracy of $0.1 \mathrm{~kg}$ ) and a stadiometer of Seca company (made in Germany with an accuracy of 1 $\mathrm{mm}$ ), respectively to calculate body mass index.

\section{Measures}

\section{Flexible ruler}

In this study, a flexible ruler (made in Iran with an accuracy of $1 \mathrm{~mm}$ ) was used to measure the lumbar arch angle. Flexible ruler has advantages, such as fast, cheap, and noninvasive measurements; the validity of measurements performed with this ruler are comparable with $\mathrm{X}$ ray measurements $(r=0.91)$. Also, the reliability within the tester is reported to be 0.82 [26]. According to the Youdas method, the thoracic $12^{\text {th }}$ spine process was considered as the starting point of the arch and the sacral was considered as the end of the arch [27]. To reach the thoracic $12^{\text {th }}$ spine process, the lower side of the $12^{\text {th }}$ rib was touched on both sides by the thumb, then, the two thumbs were simultaneously moved up and inside on both sides of the body until the ribs disappeared under the soft tissue. At this point, using an anti-allergic marker, the middle point between the two thumbs was marked as the thoracic $12^{\text {th }}$ spine process. After identifying the necessary bone markers, the subjects were asked to stand up completely naturally, spread their legs shoulder-width apart, keep their gaze forward, and place their weight equally on both feet. Then, a flexible ruler was placed on the person's lumbar spine to take the shape of the arch. After fixing the flexible ruler on the spine, the parts of the ruler that were in contact with the middle part of the labels were marked with the marker. Without any change in the shape of the flexible ruler, it was taken slowly and carefully from the body and placed on the thoracic $12^{\text {th }}$ spine process. Then, the curvature of its convex part was drawn on the paper, and the points T12 and S2 were marked on it. To calculate the degree of lumbar lordosis, the points T12 and S2 were connected. The angle of the arc was calculated in degrees using the equation $\theta=4$ $\arctan (2 \mathrm{~h} / \mathrm{l})$. In this equation, 1 is the straight line drawn from $\mathrm{T} 12$ to $\mathrm{S} 2$ and $\mathrm{H}$ is the vertical distance between the deepest part of the arc and this line [28, 29]. This process was repeated three times and their average was recorded as the total angle. Based on the angle of curvature, subjects were assigned into two groups: normal lumbar lordosis and lumbar hyperlordosis [30].

\section{Nine-test screening battery}

After recording the curvature, 9TSB was performed according to the Frohm guidelines [18]. For this purpose, the subjects repeated each movement three times by receiving specific oral instructions. Each movement was given a score from 0 to 3 , based on the quality of the performance (Table 1). The score indicates the presence of pain, inability to perform the movement pattern, the implementation of the movement pattern with compensatory movements, and complete and flawless implementation of the movement pattern. In this regard, the sum of the scores of the nine tasks determined the total score. After performing three repetitions in each movement, the best score was recorded in the score 
Table 1. Scoring instructions for Nine-test Screening Battery (9TSB)

\begin{tabular}{|c|c|c|}
\hline Tests & Figures & Scoring Criteria \\
\hline Deep squat & & $\begin{array}{l}\text { Three points: All criteria have to be fulfilled ( } 0.02 \mathrm{~m} \text { board) } \\
\text { - Straight line hip, knee, and foot } \\
\text { - Parallel feet and heels kept on the board throughout the motion } \\
\text { - Femur below horizontal } \\
\text { - Arms parallel to ears } \\
\text { - The pole is behind the toes } \\
\text { Two points: This criterion has to be fulfilled ( } 0.04 \mathrm{~m} \text { board) } \\
\text { - Same criteria as for } 3 \text { points except the use of a } 0.04 \mathrm{~m} \text { board } \\
\text { One point: One or more of the following criteria have to be fulfilled ( } 0.04 \mathrm{~m}) \\
\text { - No straight line hip, knee, and foot } \\
\text { - The feet are not parallel through the motion } \\
\text { - Femur is not below horizontal } \\
\text { - Arms are not parallel with the ears } \\
\text { - The pole is not behind the toes }\end{array}$ \\
\hline One-legged squat & & $\begin{array}{l}\text { Three points: All criteria have to be fulfilled } \\
\text { - Hip, knee, and foot aligned } \\
\text { - Pelvis in horizontal line } \\
\text { - The upper body is vertical } \\
\text { Two points: One or more of the following criteria } \\
\text { - Hip, knee, and foot aligned } \\
\text { - Pelvis is not in horizontal line } \\
\text { - The upper body is not vertical } \\
\text { One point: This criterion has to be fulfilled } \\
\text { - Hip, knee, and foot is not aligned }\end{array}$ \\
\hline In-line lunge & & $\begin{array}{l}\text { Three points: All criteria have to be fulfilled } \\
\text { - Pole contact with head and sacrum } \\
\text { - The upper elbow pointing } 90 \text { o to the side } \\
\text { - No movement of upper body with a pole vertical } \\
\text { - Contact is kept between knuckle and column } \\
\text { - Both feet in line pointing straight forward } \\
\text { - The anterior knee is straight over the anterior foot } \\
\text { - Anterior heel is kept in the plank } \\
\text { - Rearfoot touches the plank } \\
\text { Two points: One or more of the following criteria have to be fulfilled } \\
\text { - No pole contact with head and sacrum } \\
\text { - The upper elbow not pointing } 90 \text { o to the side } \\
\text { - Minor movement of upper body pole is not vertical } \\
\text { - No contact between knuckle and columna } \\
\text { - Feet is not pointing straight forward } \\
\text { - The anterior knee is not in line over foot } \\
\text { One point: One or more of the following criteria have to be fulfilled } \\
\text { - Loss of balance } \\
\text { - Rear knee is not in contact with the plank } \\
\text { - The anterior heel is not in contact with the plank }\end{array}$ \\
\hline Active hip flexion & & $\begin{array}{l}\text { Three points: The following criteria has to be fulfilled } \\
\text { - Lateral malleolus passes the pole with both knees extended and neck in the neu- } \\
\text { tral position } \\
\text { - Both knees extended and neck in neutral position at the mid-point of the first given } \\
\text { point and mid patellae } \\
\text { - The right knee is in contact with the plank } \\
\text { Two points: The following criteria has to be fulfilled } \\
\text { - Lateral malleolus passes the pole between the measurement above and mid patellae } \\
\text { - Both knees extended and neck in neutral position at half way between first pole } \\
\text { position on thigh and SAIS } \\
\text { - The right knee is in contact with the plank } \\
\text { One point: This criterion has to be fulfilled } \\
\text { - Lateral malleolus does not pass the above-given criteria }\end{array}$ \\
\hline
\end{tabular}




\begin{tabular}{|c|c|c|}
\hline Tests & Figures & Scoring Criteria \\
\hline Straight leg raises & & $\begin{array}{l}\text { Three points: The following criteria has to be fulfilled } \\
\text { - Ability to stabilize trunk with legs together, dorsiflexed feet with heels touches the } \\
\text { floor and back with retained } \\
\text { - The position of lumbar spine L4-L5 pushed towards the physiotherapist fingers } \\
\text { between the floor and the back } \\
\text { - Neck in neutral position } \\
\text { Two points: This criterion has to be fulfilled } \\
\text { - Ability to stabilize trunk with legs together, as above to } 30 \text { o } \\
\text { One point: This criterion has to be fulfilled } \\
\text { - No ability to stabilize trunk with } 30 \text { o hip flexion }\end{array}$ \\
\hline Push-up & & $\begin{array}{l}\text { Three points: Both criteria have to be fulfilled } \\
\text { - The body is pushed up as a unit facing straight down through the whole motion } \\
\text { - Contact is kept between the pole, the back of the head, and between the testers } \\
\text { fingers and lumbar spine } \\
\text { Two points: The following criteria have to be fulfilled } \\
\text { - The body is pushed up as a unit facing straight down through the whole motion } \\
\text { - Contact is not kept between stick and the back of the head or between the PTs } \\
\text { fingers and lumbar spine } \\
\text { One point: This criterion has to be fulfilled } \\
\text { - The body is not pushed up as a unit }\end{array}$ \\
\hline
\end{tabular}

Diagonal lift

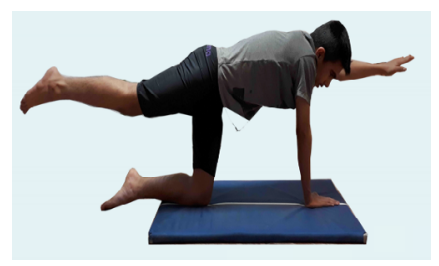

Three points: All of the following criteria have to be fulfilled

- Performs one diagonal lift with the right hand and the opposite foot and knee on a line

- No visible rotation in the spine

- Fully extended leg and arm in the horizontal plane

- No abduction in either leg or arm

- No winging of the scapula

Two points: All of the following criteria have to be fulfilled

- Performs one diagonal lift with hand and the opposite knee on each side of a line

- No visible rotation in the spine

- Fully extended leg and arm in the horizontal plane

- No abduction in either leg or arm

- No winging of the scapula

One point: One or more of the following criteria have to be fulfilled

- Performs one diagonal lift with hand and the opposite knee on each side of a line, with one or more of the following compensatory movement pattern

- Visible rotation in the spine

- Not fully extended leg and arm in the horizontal plane

- Abduction in either leg or arm

- Winging of the scapula

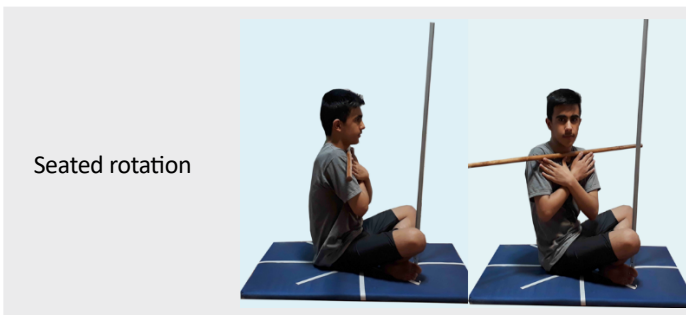

Three points: This criterion has to be fulfilled

- Performs a slow rotation with the pole in touch with the chest until the poles touch each other

Two points: This criterion has to be fulfilled

- Performs a slow rotation with the pole in touch with the chest more than 45 ․

- The poles are not touching each other

One point: This criterion has to be fulfilled

- Performs a slow rotation with the pole in touch with the chest less than 450 


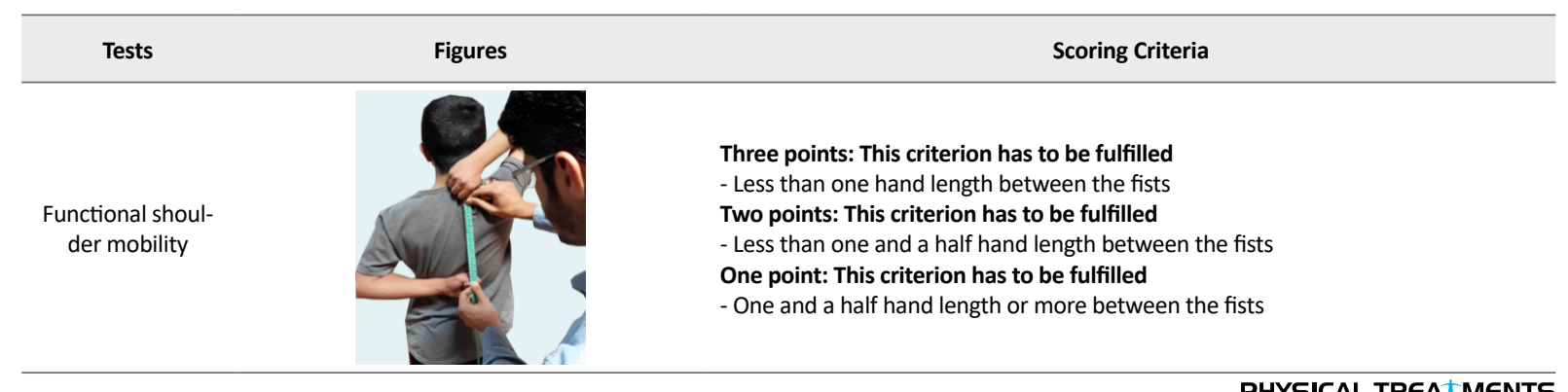

PHYSICAL TREA $\$ MENTS

sheet. Tools needed to perform 9TSB include a wooden board $60 \mathrm{~cm}$ long, $5 \mathrm{~cm}$ wide, and $4 \mathrm{~cm}$ thick; a wooden board $200 \mathrm{~cm}$ long, $10 \mathrm{~cm}$ wide, and $2 \mathrm{~cm}$ thick; and some cylindrical sticks $1 \mathrm{~m}$ long and $2 \mathrm{~cm}$ thick. The validity and reliability of this test were assessed by Frohm et al. and Rafnsson et al. [18, 31].

\section{Statistical method}

The Shapiro-Wilk test was used to determine the normal distribution of the data. Also, the forward stepwise logistic regression test was used to assess the predictability of the tests for the likelihood of lumbar hyperlordosis. Logistic regression was performed to evaluate the effect of minor variables and the total score of 9TSB on the likelihood of lumbar hyperlordosis. This model includes 10 independent variables: total score, deep squattest, single-leg squat, in-line lunge, active hip flexion, straight leg raise, push-up, diagonal lift, seated rotation, and shoulder functional mobility. All analyzes were performed using SPSS V. 24, at a significant level of 0.05 .

\section{Results}

In the present study, 60 boys aged 13 to 15 years participated in two groups of increased lumbar lordosis $(n=31)$ and normal lordosis $(n=29)$. Table 2 reports the descriptive information of the samples; both groups were homogeneous in terms of demographic characteristics. Based on the results of the Kolmogorov-Smirnov test, the data were normally distributed. Also, the independent t-test showed that the two groups did not differ in terms of demographic variables $(\mathrm{P}>0.05)$. The omnibus test related to the evaluation of the whole logistic regression model showed an acceptable model fit that was significant at the error level of less than 0.002 (Table 3). Besides, the predictor variables were related to the outcome variable $(\mathrm{N}=60)\left(\chi^{2}=12.30, \mathrm{P}<0.001\right)$. This means that predictor variables can significantly differentiate people with hyperlordosis from those with normal lordosis

This model generally predicts the possibility of lumbar hyperlordosis between $18.5 \%$ (Cox and Snell R square) to $24.7 \%$ (Nagelkerke R square) (Table 4). According to the results of the classification table of regression output, the sensitivity of the model (the percentage of people with lordosis) is accurately known through real positives in the model and the results showed that the model can correctly classify $71 \%$ of people with hyperlordosis (Table 5 ).

The results of the regression model showed that among the items of 9TSB and the total score of this test, the complete deep squat and straight leg raise items have a significant contribution to the regression model (Table 6). As observed in Table 6, examining the coefficients of significant variables in the logistic regression equation in the prediction of hyperlordosis provides important information about the contribution or significance of each of the predictor variables. The examination of the coefficients of predictive variables shows that the Wald test is statistically significant for the deep squat variable $(\mathrm{P}=0.023)$ and straight leg raise variable $(\mathrm{P}=0.033)$, and these variables significantly contributed to the model prediction ability and the probability of lumbar hyperlordosis.

The score obtained from the deep squat and straight leg raise test has a reversed and negative impact on the probability of lumbar hyperlordosis, and the odds ratio of individuals with lumbar hyperlordosis increases with lower scores in these two tests. These results show per unit increase in the deep squat-test score and straight leg raise test score, the probability of lumbar hyperlordosis reduces by 0.37 and 0.34 , respectively (Table 7 ).

\section{Discussion}

This study aimed to evaluate the capability of 9TSB in predicting lumbar hyperlordosis in adolescent boys. After performing this test and using the logistic regression test, it was found that the deep squat and the straight leg raise tests could predict the possibility of lumbar hyperlordosis.

The results of this study were inconsistent with the results of Leandersson [25]. Their results showed that none of the 9TSB and M9TSB tests had the required sensitiv- 
Table 2. Descriptive information of the study sample

\begin{tabular}{|c|c|c|c|c|}
\hline Variables & Normal Lordosis Group & Hyper Lordosis Group & Total & $\mathbf{P}$ \\
\hline Age (y) & $13.65 \pm 0.89$ & $13.77 \pm 0.84$ & $13.71 \pm 0.86$ & 0.599 \\
\hline Stature height $(\mathrm{cm})$ & $161.58 \pm 8.98$ & $160.22 \pm 8.06$ & $160.88 \pm 8.47$ & 0.539 \\
\hline Weight (kg) & $55.24 \pm 8.77$ & $57.45 \pm 7.38$ & $56.38 \pm 8.09$ & 0.295 \\
\hline BMI $\left(\mathrm{kg} / \mathrm{m}^{2}\right)$ & $21.05 \pm 1.96$ & $22.65 \pm 2.76$ & $21.88 \pm 2.52$ & 0.185 \\
\hline Lordosis angle (degree) & $38.51 \pm 5.62$ & $57.08 \pm 8.57$ & 48.73 & 0.036 \\
\hline
\end{tabular}

Table 3. Omnibus tests of model coefficients

\begin{tabular}{ccccc}
\hline & & Chi-squared & df & P \\
\hline & Steps & 7.121 & 1 & 0.008 \\
\hline & Block & 7.121 & 1 & 0.008 \\
& model & 7.121 & 1 & 0.008 \\
& Step & 5.184 & 1 & 0.023 \\
& Block & 12.305 & 2 & 0.002 \\
& model & 12.305 & 2 & 0.002 \\
\hline
\end{tabular}

ity and specificity to predict lower limb injuries. Also, our results were inconsistent with the results of Bakken [24]. Their results showed that none of the tests had the sensitivity and specificity needed to predict damage to the lower limbs. As it turns out, the partial tests of 9TSB do not just focus on the lower limbs, they challenge the lower back and pelvis more than other areas. However, the lower limbs are used more than the others, in football and orienteering. For example, most football-related injuries are to the lower limbs, such as the ankles, thighs, and knees [32]. Also, external risk factors play a significant role, in addition to the internal risk factors, such as defects in movement patterns.

On the other hand, Bakken et al. only considered the general score, besides, the scores of the partial tests were not considered as a predictive factor. The same is true in the field of orienteering; most of the injuries in this field are related to the soles of the feet, knees, and ankles [33], where the excessive activity and floor surface are among the risk factors. As mentioned, 9TSB is optimized to challenge and test the dynamic function of the trunk's flexor muscles and spinal rotators [18]. Hence, the reasons for this inconsistency can be the incompatibility of the functional characteristics of the test with the factors of the desired damage and the nature and biomechanical and functional characteristics of the two sports of orienteering and football.

Also, the results were inconsistent with the findings of Allafan et al. [22]. They reported that of all the FMS partial tests, the forward step and active hip flexion tests could predict the probability of nonstructural scoliosis [22]. The quality of the pelvic and lumbar movement pattern depends to a considerable extent on the function of different muscle groups as force pairs in the pelvic girdle and lumbar spine. The optimal length-tension relationship of muscles is a very important factor in controlling posterior and anterior pelvic tilt. As it turns out, the subject in the straight leg raise test must stabilize the position of the lumbar spine and pelvic girdle and maintain it unchanged, while performing the hip extension movement with the adequate control of the flexor hip muscles with an eccentric contraction. This requires appropriate contraction of the localized stabilizing muscles of the pelvic lumbar region, ie, the abdominal group, the deep muscles of the spine, and finally abdominal box, in the isometric form.

As performing the Straight leg raise, the poor function of the core stabilizing muscles should cause compensatory movements to appear in the lumbar spine. In this way, Mitchell et al. demonstrated a significant relationship between the strength and balance of the stabilizing muscles 
Table 4. Model summary

\begin{tabular}{cccc}
\hline Steps & $-\mathbf{2}$ log-likelihood & Cox \& Snell R Square & Nagelkerke R Square \\
\hline 1 & $75.990 \mathrm{a}$ & 0.112 & 0.149 \\
2 & $70.806^{\mathrm{a}}$ & 0.185 & 0.247 \\
\hline
\end{tabular}

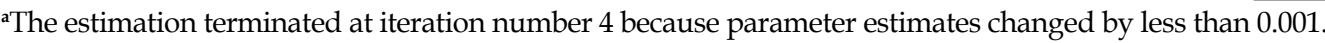

Table 5. Logistic regression equation

\begin{tabular}{|c|c|c|c|c|}
\hline \multicolumn{2}{|c|}{ Observed } & \multirow{2}{*}{$\begin{array}{c}\text { Normal } \\
17\end{array}$} & \multirow{2}{*}{$\begin{array}{c}\text { Lordosis } \\
\qquad 12\end{array}$} & \multirow{2}{*}{$\begin{array}{c}\text { Percentage Correc } \\
58.6\end{array}$} \\
\hline & Normal & & & \\
\hline \multirow[t]{3}{*}{ Step 1} & Lordosis & 7 & 24 & 77.4 \\
\hline & Overall percentage & - & - & 68.3 \\
\hline & Normal & 20 & 9 & 69 \\
\hline \multirow[t]{2}{*}{ Step 2} & Lordosis & 9 & 22 & 71 \\
\hline & Overall percentage & & & 70 \\
\hline
\end{tabular}

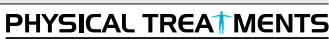

of the core of the body and the quality of functional movement pattern, especially in the lumbopelvic region [34]. On the other hand, in the straight leg raise test, we are measuring the strength of the flexor muscles of the hip. This movement is performed by the iliopsoas muscle, which plays the prime movers role. Because this muscle is in the tightnessweakness position, in lumbar hyperlordosis, it is unable to control movement; this will increase lumbar arching as it continues to move. Finally, the weakness of the abdominal muscles, especially the rectus abdominis muscle in controlling the second phase of the straight leg raise movement, causes the excessive anterior tilt of the pelvis, which helps to create an excessive arch in the lumbar region.

The forward movement of the hands is one of the most obvious errors in the deep squat-test. This error is due to the limitation in the flexion of the shoulder joint and the incompleteness of the range of motion. This could be caused by the shortening of the latissimus dorsi muscle, which is evident in people with lumbar hyperlordosis. Other errors in this test include moving the knee joint forward and crossing the toes. This compensatory movement is usually due to the tendency of people to overuse the quadriceps muscles and minimize the use of the gluteus muscles, because of weakness and defects in the nervous and muscular system [35].

For the squat-test, the proper functioning of the types of slings is necessary, especially in the longitudinal and posterior direction in the spinal and pelvic areas, as well as the longitudinal and oblique direction in the chest and pelvic areas for the straight leg raise test. Also, establishing optimal and correct communication with adjacent slings can prevent movement restrictions and minimize compensatory movements [36]. So, people with lumbar hyperlordosis experience a weakness in the core area of the body, owing to the function of specific muscles that act as local stabilizers in the joints and provide proprioceptive feedback in static situations. Also, due to the inefficiency of multi-joint muscles, these individuals suffer from active weakness. Usually, two or more joint muscles lack normal function in applying sufficient tension, contraction, and length reduction to simultaneously complete the full range of motion in all joints. Finally, this condition is associated with changes in joint direction and muscle weakness in proper functioning and providing proprioceptive feedback in dynamic situations, which is noted by Cook et al. [37].

Individuals with natural lordosis are better prepared and able to perform tasks and challenges in this area, because of their good condition in the mentioned cases, such as the test for straight leg raise and the deep squattest. For this reason, the mentioned tests can be considered as suitable predictors.

Among the limitations of the present study is the lack of the evaluation of the ability of this test in predicting the occurrence of lumbar lordosis in active and inactive people, failure to compare this issue between men and wom- 
Table 6. Logistic regression-variables in the equation

\begin{tabular}{|c|c|c|c|c|c|c|c|c|}
\hline Variables & B & S.E & WALD & Df & $\mathbf{P}$ & $\operatorname{Exp}(B)$ & Lower & Upper \\
\hline Total score & -2.18 & 1.58 & 1.89 & 1 & 0.16 & 0.11 & 0.005 & 2.51 \\
\hline Deep squat & 0.97 & 1.61 & 0.36 & 1 & 0.54 & 2.64 & 0.11 & 62.46 \\
\hline Single leg squat (R) & 1.28 & 1.06 & 1.44 & 1 & 0.22 & 3.61 & 0.44 & 29.39 \\
\hline Single leg squat (L) & 1.37 & 0.97 & 1.97 & 1 & 0.16 & 3.95 & 0.58 & 26.91 \\
\hline In-line lunge (R) & 1.71 & 1.05 & 2.65 & 1 & 0.10 & 5.55 & 0.7 & 43.78 \\
\hline In-line lunge (L) & 0.93 & 1.1 & 0.66 & 1 & 0.41 & 2.55 & 0.28 & 24.33 \\
\hline Active hip flexion (R) & 1.16 & 1.14 & 1.03 & 1 & 0.31 & 3.19 & 0.33 & 30.14 \\
\hline Active hip flexion (L) & 0.31 & 1.08 & 0.08 & 1 & 0.77 & 1.36 & 0.16 & 11.36 \\
\hline Straight leg raise & 3.53 & 1.92 & 3.36 & 1 & 0.06 & 34.11 & 0.78 & 1482.47 \\
\hline Push-up & 1.28 & 1.45 & 0.77 & 1 & 0.37 & 3.6 & 0.2 & 62.47 \\
\hline Diagonal lift (R) & -0.35 & 0.97 & 0.13 & 1 & 0.71 & 0.7 & 0.1 & 4.47 \\
\hline Diagonal lift (L) & 1.65 & 1.04 & 2.51 & 1 & 0.11 & 5.22 & 0.67 & 40.35 \\
\hline Seated rotation $(\mathrm{R})$ & 0.40 & 1.18 & 0.11 & 1 & 0.73 & 1.5 & 0.14 & 15.27 \\
\hline Seated rotation (L) & 1.91 & 1.30 & 2.14 & 1 & 0.14 & 6.79 & 0.52 & 88.15 \\
\hline Functional shoulder mobility & 2.00 & 1.70 & 1.39 & 1 & 0.23 & 7.43 & 0.26 & 208.62 \\
\hline Constant & 3.18 & 3.47 & 0.84 & 1 & 0.35 & 24.6 & - & - \\
\hline
\end{tabular}

PHYSICAL TREA $\ M E N T S$

Table 7. Variables in the equation

\begin{tabular}{|c|c|c|c|c|c|c|c|c|c|}
\hline \multirow{2}{*}{ Steps } & \multirow{2}{*}{ Variables } & \multirow{2}{*}{$\beta$} & \multirow{2}{*}{ SE } & \multirow{2}{*}{ WALD } & \multirow{2}{*}{ Df } & \multirow{2}{*}{ Sig. } & \multirow{2}{*}{ OD } & \multicolumn{2}{|c|}{ 95\% Confidence Interval Odd Ratio } \\
\hline & & & & & & & & Down & Up \\
\hline \multirow{3}{*}{ Step 1} & Deep squat & -1.029 & 0.41 & 6.26 & 1 & 0.12 & 0.357 & 0.16 & 0.8 \\
\hline & & & & & & & & & \\
\hline & Constant & 2.384 & 0.975 & 5.97 & 1 & 0.15 & 10.84 & - & \\
\hline \multirow{3}{*}{ Step 2} & Deep squat & -0.969 & 0.42 & 5.19 & 1 & 0.023 & 0.379 & 0.165 & 0.873 \\
\hline & $\begin{array}{l}\text { Straight leg } \\
\text { raise }\end{array}$ & -1.059 & 0.49 & 4.57 & 1 & 0.023 & 0.347 & 0.131 & 0.916 \\
\hline & Constant & 4.45 & 1.45 & 9.33 & 1 & 0.002 & 85.8 & - & - \\
\hline
\end{tabular}


en, not examining it for different age groups, low sample size, and nonuse of radiography as a standard method.

\section{Conclusion}

According to the findings of this study, 9TSB has a better ability to measure movement patterns related to spinal abnormalities, compared with the other screening tests. Also, among 9TSB components, deep squat and straight leg raises tests are proper factors for predicting the occurrence of lumbar hyperlordosis in adolescent boys.

\section{Ethical Considerations}

\section{Compliance with ethical guidelines}

The present study is approved by the Ethics Committee of the University of Tehran (Code: IR.UT.SPORT. REC.1398.026.

\section{Funding}

This research received no specific grant from funding agencies in the public, commercial, or non-profit sectors.

\section{Authors' contributions}

All authors equally contributed to the present study.

\section{Conflict of interest}

The authors declared no conflicts of interest.

\section{References}

[1] Clark M, Lucett S, National Academy of Sports Medicine. London: NASM essentials of corrective exercise training: Lippincott Williams \& Wilkins; 2010. https:/ / books. google.com/books?id=tZGIM2xzeSwC\&dq

[2] Nishida M, Nagura T, Fujita N, Hosogane N, Tsuji T, Nakamura M, et al. Position of the major curve influences asymmetrical trunk kinematics during gait in adolescent idiopathic scoliosis. Gait \& Posture. 2017; 51:142-8. [DOI:10.1016/j.gaitpost.2016.10.004] [PMID]

[3] Daryabor A, Arazpour M, Sharifi G, Bani MA, Aboutorabi A, Golchin N. Gait and energy consumption in adolescent idiopathic scoliosis: A literature review. Annals of Physical and Rehabilitation Medicine. 2017; 60(2):107-16. [DOI:10.1016/j.rehab.2016.10.008] [PMID]

[4] Bandy WD, Irion JM, Briggler M. The effect of time and frequency of static stretching on flexibility of the ham- string muscles. Physical Therapy. 1997; 77(10):1090-6. [DOI:10.1093/ptj/77.10.1090] [PMID]

[5] Bae TS, Mun M. Effect of lumbar lordotic angle on lumbosacral joint during isokinetic exercise: A simulation study. Clinical Biomechanics. 2010; 25(7):628-35. [DOI:10.1016/j.clinbiomech.2010.04.004] [PMID]

[6] Vaz G, Roussouly P, Berthonnaud E, Dimnet J. Sagittal morphology and equilibrium of pelvis and spine. European Spine Journal. 2002; 11(1):80-7. [DOI:10.1007/ s005860000224] [PMID] [PMCID]

[7] Vialle R, Levassor N, Rillardon L, Templier A, Skalli W, Guigui P. Radiographic analysis of the sagittal alignment and balance of the spine in asymptomatic subjects. The Journal of Bone and Joint Surgery. 2005; 87(2):260-7. [DOI:10.2106/00004623-200502000-00004] [PMID]

[8] Been E, Kalichman L. Lumbar lordosis. The Spine Journal. 2014; 14(1):87-97. [DOI:10.1016/j.spinee.2013.07.464] [PMID]

[9] Purcell L. Causes and prevention of low back pain in young athletes. Paediatrics \& Child Health. 2009; 14(8):533-8. [DOI:10.1093/pch/14.8.533] [PMID] [PMCID]

[10] Patichok A, Didor MD. Children's physical growth, programs for recognition and corrective for abnormality spine. 2001. https://scholar.google.com/scholar?hl=en\&as_sdt $=0 \% 2 \mathrm{C} 5 \& \mathrm{q}$

[11] Nazarian AB, Daneshjoo A, Ghorbani L, Ghaedi H. [The prevalence of lordotic and kyphotic deformities among different age groups (Persian)]. Journal of Research in Rehabilitation Sciences. 2010; 5(1):24-32. http://jrrs.mui.ac.ir/index. $\mathrm{php} / \mathrm{jrrs} /$ article/view/35

[12] Cook G, Burton L, Hoogenboom BJ, Voight M. Functional movement screening: the use of fundamental movements as an assessment of function-part 1. International Journal of Sports Physical Therapy. 2014; 9(3):396-409. [PMID] [PMCID]

[13] O'Connor FG, Deuster PA, Davis J, Pappas CG, Knapik JJ. Functional movement screening: Predicting injuries in officer candidates. Medicine \& Science in Sports \& Exercise. 2011; 43(12):2224-30. [DOI:10.1249/MSS.0b013e318223522d] [PMID]

[14] de Vreede PL, Samson MM, van Meeteren NL, van der Bom JG, Duursma SA, Verhaar HJ. Functional tasks exercise versus resistance exercise to improve daily function in older women: A feasibility study. Archives of Physical Medicine and Rehabilitation. 2004; 85(12):1952-61. [DOI:10.1016/j. apmr.2004.05.006] [PMID]

[15] Bahr R. No injuries, but plenty of pain? On the methodology for recording overuse symptoms in sports. British Journal of Sports Medicine. 2009; 43(13):966-72. [DOI:10.1136/ bjsm.2009.066936] [PMID]

[16] Whiteside D, Deneweth JM, Pohorence MA, Sandoval B, Russell JR, McLean SG, et al. Grading the functional movement screen: A comparison of manual (real-time) and objective methods. The Journal of Strength \& Conditioning Research. 2016; 30(4):9:24-33 [DOI:10.1519/ JSC.0000000000000654] [PMID]

[17] Mitchell UH, Johnson AW, Vehrs PR, Feland JB, Hilton SC. Performance on the Functional Movement Screen in older active adults. Journal of Sport and Health Science. 2016; 5(1):11925. [DOI:10.1016/j.jshs.2015.04.006] [PMID] [PMCID] 
[18] Frohm A, Heijne A, Kowalski J, Svensson P, Myklebust G. A nine-test screening battery for athletes: A reliability study. Scandinavian Journal of Medicine \& Science in Sports. 2012; 22(3):306-15. [DOI:10.1111/j.1600-0838.2010.01267.x] [PMID]

[19] Bonazza NA, Smuin D, Onks CA, Silvis ML, Dhawan A. Reliability, validity, and injury predictive value of the functional movement screen: A systematic review and metaanalysis. The American Journal of Sports Medicine. 2017; 45(3):725-32. [DOI:10.1177/0363546516641937] [PMID]

[20] Zandi S, Mirzarah-Koshki MH, Montazeri Taleghani H. [Injury prediction in recreational sports using functional movement screening test (Persian)]. Journal of Exercise Science and Medicine. 2018; 9(2):259-68. [DOI:10.22059/JSMED.2018.253883.882]

[21] Shojaedin SS, Hadadnezhad H. [Relationship between Functional Movement Screen (FMS) score and the history of injury and identify the predictive value of the FMS (Persian)]. Journal of Research in Rehabilitation Sciences. 2013; 9(3):459-69. http:/ / jrrs.mui.ac.ir/index.php/jrrs/article/view/967

[22] Allafan N, Rajabi R, Shahrbanian S, Minoonejad H. [Can functional movement screen test predict nonstructural scoliosis in university girl students? (Persian)] Journal of Research in Rehabilitation Sciences. 2018; 14(1):9-14. [DOI:10.22122/jrrs. v14i1.3113]

[23] Bakken A, Targett S, Bere T, Eirale C, Farooq A, Tol JA, et al. Interseason variability of a functional movement-test, the $9+$ screening battery, in professional male football players. British Journal of Sports Medicine. 2016; 51(14):1081-6. [DOI:10.1136/ bjsports-2016-096570] [PMID]

[24] Bakken A, Targett S, Bere T, Eirale C, Farooq A, Tol JL, et al. The functional movement-test $9^{+}$is a poor screening test for lower extremity injuries in professional male football players: A 2-year prospective cohort study. British Journal of Sports Medicine. 2018; 52(16):1047-53. [DOI:10.1136/bjsports-2016-097307] [PMID]

[25] Leandersson J, Heijne A, Flodström F, Frohm A, von Rosen P. Can movement-tests predict injury in elite orienteerers? A 1-year prospective cohort study. Physiotherapy Theory and Practice. 2020; 36(8):956-64. [DOI:10.1080/09593985.2018.15131 06] [PMID]

[26] Rajabi R, Samadi H. [Laboratory of corrective exercises ( $3^{\text {rd }}$ edition) (Persian)]. Tehran: University of Tehran Publication; 2019. https://press.ut.ac.ir/book_712.html

[27] Youdas JW, Garrett TR, Harmsen S, Suman VJ, Carey JR. Lumbar lordosis and pelvic inclination of asymptomatic adults. Physical Therapy. 1996; 76(10):1066-81. [DOI:10.1093/ptj/76.10.1066] [PMID]

[28] Burton AK. Regional lumbar sagittal mobility; Measurement by flexicurves. Clinical Biomechanics. 1986; 1(1):20-6. [DOI:10.1016/0268-0033(86)90032-X]

[29] Hart DL, Rose SJ. Reliability of a noninvasive method for measuring the lumbar curve. Journal of Orthopaedic \& Sports Physical Therapy. 1986; 8(4):180-4. [DOI:10.2519/jospt.1986.8.4.180] [PMID]

[30] Reza R, Sepideh L. [Norms of thoracic region and lumbar region of spine in Iranian men and women (Persian)]. Sports Medicine Studies. 2010; 2(7):1-28. https:/ / civilica.com/doc/793347/
[31] Rafnsson ET, Frohm A, Myklebust G, Bahr R, Valdimarsson Ö, Árnason Á. Nine test screening battery-intra-rater reliability and screening on icelandic male handball players. British Journal of Sports Medicine. 2014; 48(7):674. [DOI:10.1136/bjsports-2014-093494.307]

[32] Roos KG, Wasserman EB, DaltonSL, Gray A, Djoko A, Dompier $\mathrm{TP}$, et al. Epidemiology of 3825 injuries sustained in six seasons of National Collegiate Athletic Association men's and women's soccer (2009/2010-2014/2015). British Journal of Sports Medicine. 2017; 51(13):1029-34. [DOI:10.1136/bjsports-2015-095718] [PMID]

[33] von Rosen P, Floström F, Frohm A, Heijne A. Injury patterns in adolescent elite endurance athletes participating in running, orienteering, and cross-country skiing. International Journal of Sports Physical Therapy. 2017; 12(5):822-32. [DOI:10.26603/ ijspt20170822] [PMID] [PMCID]

[34] Mitchell UH, Johnson AW, Adamson B. Relationship between functional movement screen scores, core strength, posture, and body mass index in school children in Moldova. The Journal of Strength \& Conditioning Research. 2015; 29(5):1172-9. [DOI:10.1519/JSC.0000000000000722] [PMID]

[35] Kendall FP, McCreary EK, Provance PG. Muscles, testing and function: With posture and pain. Baltimore Williams \& Wilkins; 1993. https://books.google.com/ books?id=kwTnJwAACAAJ\&dq

[36] Liem T, Chila A, Tozzi P. Fascia in the osteopathic field. Pencaitland: Handspring Publishing Limited; 2017. https:/ / books.google.com/books?id=xRaToAEACAAJ\&dq

[37] Cook G. Movement: Functional movement systems: Screening, assessment and corrective strategies. Santa Cruz: On Target Publications; 2010. https://books.google.com/ books?id=iOadmwEACAAJ\&dq 